Original Article

\title{
INVESTIGATION OF THE SYNERGISTIC ANTIBACTERIAL ACTION OF COPPER NANOPARTICLES ON CERTAIN ANTIBIOTICS AGAINST HUMAN PATHOGENS
}

\author{
M. SELVARANI ${ }^{*}$ \\ Department of Zoology, V. V. Vanniaperumal College for Women (Autonomous), Virudhunagar 626001, Tamil Nadu, India \\ Email: selvarani.msrani@gmail.com
}

Received: 22 Jun 2018 Revised and Accepted: 03 Sep 2018

\begin{abstract}
Objective: Resistance to antibacterial agents by pathogenic bacteria has emerged in recent years and is a major challenge for the healthcare industry. Copper nanoparticles (CuNPs) are known to be one of the multifunctional inorganic nanoparticles with effective antibacterial activity. Hence the present investigation has been focused on synthesizing and evaluating the bactericidal effect of copper nanoparticles.

Methods: CuNPs were synthesized by reducing the aqueous solution of copper sulfate with sodium borohydride. The synthesized particles were characterized by x-ray diffractogram (XRD), scanning electron microscopy (SEM) and energy dispersive spectroscopy (EDS) techniques to analyze size, morphology and quantitative information respectively. The antibacterial activity of CuNPs was examined by agar well diffusion method. Synergistic effect of CuNPs with broad-spectrum antibiotics was determined by the agar disc diffusion method.

Results: Color change of reaction mixture from blue to dark brown indicated the formation of CuNPs. SEM image clearly demonstrated that the synthesized particles were spherical in shape and its size was found to be $17.85 \mathrm{~nm}$. EDS report confirmed the presence of elemental copper in the resultant nanoparticles and its accounts for major proportion (96\%) of the mass of nanoparticles. Bacterial effect of CuNPs revealed that Pseudomonas aeruginosa showed the highest antibacterial sensitivity $(16.00 \pm 1.63 \mathrm{~mm})$, whereas least susceptibility $(9.67 \pm 0.47 \mathrm{~mm})$ was noticed against Staphylococcus aureus. An enhanced antibacterial activity of commercial antibiotics was also noticed when it combined with CuNPS. A minimum zone of inhibition was increased from $0.67 \pm 0.47 \mathrm{~mm}$ to $10.66 \pm 0.24 \mathrm{~mm}$ when the nanoparticles and antibiotics were given together.
\end{abstract}

Conclusion: It was observed that copper nanoparticles exhibited profound activity against all the tested bacterial strains which shows that CuNPs may serve as a better option for use in medicine in the future.

Keywords: Copper nanoparticles, Bacterial pathogens, Antibacterial activity, Zone of inhibition, Antibiotics, Synergistic effect

(C) 2018 The Authors. Published by Innovare Academic Sciences Pvt Ltd. This is an open access article under the CC BY license (http://creativecommons.org/licenses/by/4.0/] DOI: http://dx.doi.org/10.22159/ijpps.2018v10i10.28069

\section{INTRODUCTION}

Emerging infectious diseases and the increase in the incidence of drug resistance among pathogenic bacteria have made the search for new antimicrobials inevitable. Nanotechnology offers opportunities to reexplore the biological properties of already known antimicrobial compounds by manipulating their size to alter the effect [1]. In recent years, metal nanoparticles (Me-NPs) have received tremendous scientific and practical interest which exhibit novel chemical and physical properties owing to their extremely small dimensions and special surface area [2]. Among the noble metal nanoparticles, copper nanoparticles (CuNPs) have attracted great attention because of their catalytic and optical properties, high electrical and heat conductivity [3]. Copper $(\mathrm{Cu})$ has also long been known to have antimicrobial activity and is used in drinking water treatment and transportation. It has been recognized by the American environmental protection agency (EPA) as the first metallic antimicrobial agent in 2008 [4]. Though numerous methods are available for the synthesis of CuNPs, chemical reduction in aqueous or organic solvents exhibits the greatest feasibility because of simple equipment, short process, low cost and easy industrial production [5]. Bactericidal effect of CuNPs has been attributed to their small size and high surface to volume ratio, which allows them to interact closely with microbial membrane and is not merely due to the release of metal ions in solution [6]. Copper ions are known to penetrate bacteria and disrupt molecular pathways important for their survival. The antibacterial property of CuNPs was attributed mainly to adhesion with bacteria because of their opposite electrical charges, resulting in a reduction reaction at the bacterial cell wall [7]. The copper-fluoro polymer nano-composite is employed as bioactive coatings that are capable of inhibiting the growth of target microorganisms such as Saccharomyces cerevisiae, Escherichia coli, Staphylococcus aureus and Listeria [8]. Copper nanoparticles showed more inhibitory effect in bacteria than fungus
[9]. Therefore the objective of the present study was to fabricate and investigate the antibacterial efficacy of copper nanoparticles and the combinatorial effect of nanoparticles impregnated along with major broad-spectrum antibiotics.

\section{MATERIALS AND METHODS}

\section{Materials}

Copper sulfate pentahydrate $\left(\mathrm{CuSO}_{4} .5 \mathrm{H}_{2} \mathrm{O}\right)$, sodium citrate $\left(\mathrm{Na}_{3} \mathrm{C}_{6} \mathrm{H}_{5} \mathrm{O}_{7}\right)$, sodium borohydride $\left(\mathrm{NaBH}_{4}\right)$, ethanol, nutrient broth Mueller Hinton agar, and standard antibiotic discs were purchased from Himedia (P) Ltd. Mumbai and used as starting materials without further purification. Milli-Q water was used for the fabrication of nanoparticles.

\section{Methods}

\section{Preparation of copper nanoparticles}

Copper nanoparticles were prepared by aqueous phase chemical reduction of cupric salt solution using sodium borohydride in the presence of sodium citrate as a capping agent [10]. In brief, $10 \mathrm{ml}$ of $0.0125 \mathrm{M} \mathrm{CuSO}_{4} .5 \mathrm{H}_{2} \mathrm{O}$ solution was purged with nitrogen $\left(\mathrm{N}_{2}\right)$ gas for $10 \mathrm{~min}$ to remove dissolved oxygen (DO) and then $10 \mathrm{ml}$ of $0.2 \mathrm{M}$ sodium citrate solution was added. The reaction solution was allowed to stir for $30 \mathrm{~min}$. Then $1 \mathrm{ml}$ of aqueous solution of $\mathrm{NaBH}_{4}$ $(0.1 \mathrm{M})$ was added dropwise to it under constant stirring. The entire experiment was carried out under $\mathrm{N}_{2}$ atmosphere. The solution color changed to dark brown on the complete addition of reducing agent indicating the formation of citrated capped copper nanoparticles. The particles were then collected by ultracentrifugation of resultant solution at $10,000 \mathrm{rpm}$ for $1 \mathrm{~h}$. The particles thus obtained were washed twice with acetone before being vacuum dried at $50{ }^{\circ} \mathrm{C}$ for $12 \mathrm{~h}$ to remove water. The dried particles were used for further analysis. 


\section{Characterization of copper nanoparticles}

Formation of copper nanoparticles in the reaction mixture was primarily monitored by observing the color change of reaction solution. The phase purity and crystalline structure of the synthesized CuNPs were identified by XRD pattern. XRD pattern was recorded with an X'pert PROPAN analytical instrument operated at $40 \mathrm{kV}$ and a current of $30 \mathrm{~mA}$ with Cu $\alpha$ radiation $(\lambda=1.54060 \AA)$. A continuous scan mode was used to collect $2 \theta$ data from $10.08^{\circ}$ to $79.93^{\circ}$, and the diffraction intensities were compared with the standard JCPDS. Average size of the resultant particles was calculated using Debye-Scherer's formula, $D=k \lambda / \beta \operatorname{Cos} \theta$, Where $D$ is the thickness of the nanoparticle, ' $k$ ' constant, ' $\lambda$ ' is the wavelength of $x$-rays, ' $\beta$ ' is the width at half maxima of reflection at Bragg's angle 2 $2 \theta$, ' $\theta$ ' Bragg's angle. Surface morphology and size distribution of the prepared CuNPs was examined by SEM (SU 1510) operated at $5 \mathrm{kV}$ with a magnification of about $10 \mathrm{k}$. The quantitative information and distribution of the elemental copper were investigated by EDS instrument (JSM 35 CF JEOL) in a resolution of $60 \AA$, operated at $15.0 \mathrm{kV}$ with a magnification of about $5 \mathrm{k}$

\section{Antibacterial screening of copper nanoparticles}

The selected pathogenic bacterial strains in the present experiment namely Bacillus cereus (MTCC 619), Escherichia coli (MTCC 4296), Pseudomonas aeruginosa (MTCC 424) and Staphylococcus aureus (MTCC 3160) were procured from microbial type culture collection (MTCC), Chandigarh, India. All the cultures were grown on nutrient agar plates and maintained in the nutrient agar slants at $4{ }^{\circ} \mathrm{C}$. Overnight culture in the nutrient broth was used for the antibacterial study. The screening of copper nanoparticles for its bactericidal effect was determined by the agar well diffusion method [11]. Disc diffusion assay was adopted to investigate the synergistic effect of CuNPs with commonly used antibiotics [12]. To determine the synergistic effect, each broad-spectrum antibiotic disc (Tetracycline, Rifampicin Chloramphenicol, Vancomycin, Gentamycin, Streptomycin, Kanamycin, Tobramycin, Penicillin, and Ampicillin) was impregnated with $50 \mu \mathrm{l}$ of freshly prepared CuNPs and was placed onto the sterile Mueller Hinton agar plates inoculated with tested pathogenic strains. Antibiotic discs without CuNPs were served as positive control. These plates were incubated overnight at room temperature. After incubation, results were recorded by measuring the diameter of the inhibition zone $(\mathrm{mm})$. The assay was performed in triplicates. Percentage fold increase of individual antibiotics was calculated using the formula,

$$
\text { Fold increase (\%) }=\frac{(b-a)}{a} X 100
$$

Where $\mathrm{b}$ and a represent the zone of inhibition area of antibiotics with and without copper nanoparticles.

\section{RESULTS AND DISCUSSION}

\section{Synthesis and characterization of copper nanoparticles}

The appearance of dark brown coloration in the reaction mixture clearly indicated the formation of colloidal copper (fig. 1). These color changes is due to the excitation of plasmon resonance with a significant contribution from interband transition [13]. Shahverdi et al. [14] reported that appearance of dark brown color in the reaction solution indicated the formation of copper nanoparticles and this color arises from excitation of surface plasmon vibration in the metal nanoparticles.

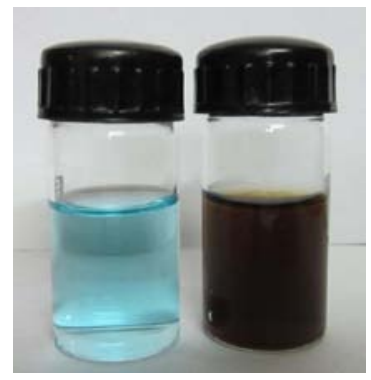

Fig. 1: Formation of dark brown color colloidal copper (right)
The X-ray diffraction pattern recorded for fabricated copper nanoparticles in the present study is shown in fig. 2 . The diffraction peaks observed at $2 \theta$ value of $43.47^{\circ}, 53.37^{\circ}$, and $74.50^{\circ}$ belong to the face-centered cubic $(\mathrm{fcc})$ metallic $\mathrm{Cu}$. The diffraction peaks appear at an angle $43.47^{\circ}, 53.37^{\circ}$ and $74.50^{\circ}$ correspond to (111), (200) and (220) sets of lattice planes of fcc structure of metallic copper ions revealing that the fabricated CuNPs were composed of pure crystalline copper. XRD pattern obtained in the present investigation was found to be in good agreement with the earlier report by Mukhopadhyay et al. [15] who examined the XRD peaks at $2 \theta$ value of $43.36^{\circ}, 50.48^{\circ}$ and $74.15^{\circ}$ corresponding to (111), (200) and (220) lattice planes of fcc structure of CuNPs respectively. Similarly, three Bragg's diffraction peaks at $2 \theta$ values of $42.47^{\circ}, 51.73$ $\circ$ and $73.42^{\circ}$ which could be indexed as (111), (200) and (220) reflection planes of fcc structure of zero-valent CuNPs [16]. Moreover, the obviously broadened diffraction peaks noticed in the given XRD pattern suggest that the resultant nanoparticles should have a very small crystallite size and its size was found to be $17.85 \mathrm{~nm}$.

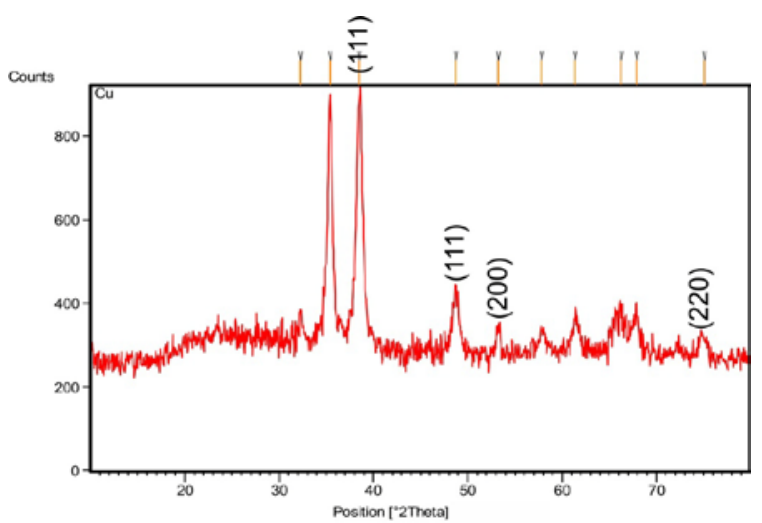

Fig. 2: Powder X-ray diffraction pattern of copper nanoparticles

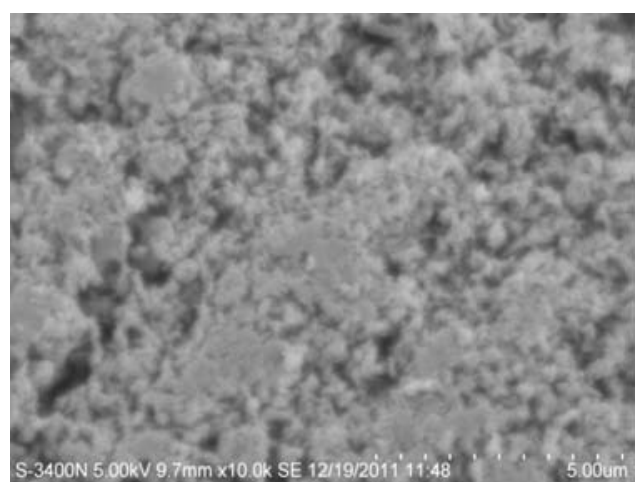

Fig. 3: Scanning electron micrograph of copper nanoparticles

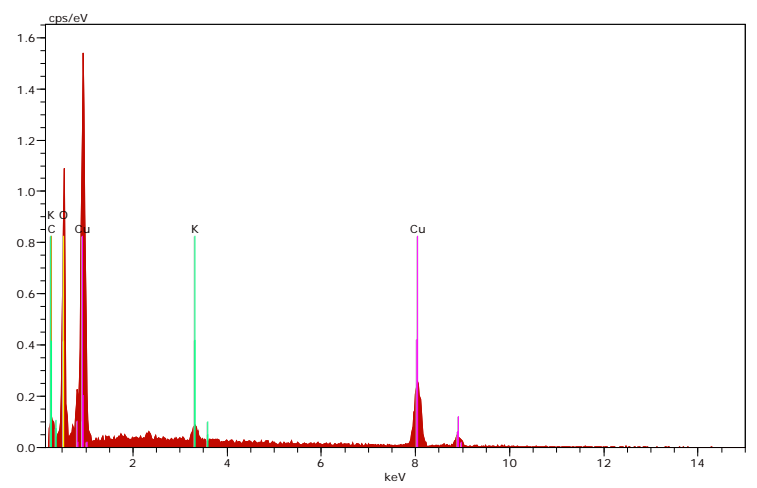

Fig. 4: Energy dispersive spectrum of copper nanoparticles 
Scanning electron micrograph of the synthesized copper nanoparticles is given in fig. 4. The micrograph shows that the appearance of the nanoparticles is spherical in shape. The resultant nanoparticles do not appear as a discrete one but form much larger particles. The observations of such larger nanoparticles were composed of van der waals clusters of smaller entities [6]. The size and shape of the nanoparticles may depend on many parameters such as the choice of reduction technique, the concentration of metal precursors, reductant and capping agents used [17].

Fig. 4 explains the atomic surface distribution and chemical composition of copper nanoparticles. The given EDS spectrum revealed the presence of an elemental copper signal. Strong signals from copper atoms $(97.07 \%$ in mass) while weaker signals from potassium $(\mathrm{K})$, carbon $(\mathrm{C})$ and oxygen $(\mathrm{O})$ were also observed. The resultant EDS spectrum of CuNPs clearly indicating that copper was in major proportion accounting for about $96 \%$ of the mass of nanoparticles. In accordance with these, the same type of elemental $\mathrm{Cu}$ signal in the EDS spectrum of CuNPs was observed in an earlier report [18]. The formation of an elemental copper signal in the EDS spectrum is due to the surface plasmon resonance where CuNPs shows absorption peaks of higher counts [19].

\section{Antibacterial screening of copper nanoparticles}

The emergence of nanoscience and nanotechnology in the last decade presents opportunities for exploring the bactericidal effect of metal nanoparticles. In the present experiment, colloidal copper showed highly potent antibacterial activity towards tested pathogenic bacterial strains. Resultant zone of inhibition is ranged from $9.67 \pm 0.47 \mathrm{~mm}$ to $16.00 \pm 1.63 \mathrm{~mm}$ (table 1 ).

Table 1: Bactericidal effect of nano copper against selected pathogens

\begin{tabular}{ll}
\hline Bacterial pathogens & Zone of inhibition (mm) \\
\hline Escherichia coli & $13.00 \pm 2.83$ \\
Pseudomonas aeruginosa & $16.00 \pm 1.63$ \\
Bacillus cereus & $12.17 \pm 0.24$ \\
Staphylococcus aureus & $9.67 \pm 0.47$ \\
\hline
\end{tabular}

Each value is the mean $\pm \mathrm{SD}$ of triplicate analysis

Diameter of inhibition zone (DIZ) reflects the magnitude of susceptibility of the bacterial species. Among the different pathogens tested, Pseudomonas aeruginosa offered maximum inhibitory zone $(16.00 \pm 1.63 \mathrm{~mm})$ whereas least susceptibility was noticed against Staphylococcus aureus $(9.67 \pm 0.47 \mathrm{~mm})$. The excellent antibacterial activity against all the selected bacterial pathogens is due to the multitarget nature of copper. The multi-target nature of copper makes resistance extremely unlikely as copper kills bacteria very quickly and leaves no survivors. Even though the exact mechanism behind the bactericidal effect of copper nanoparticles is not clearly known, but the action of copper on bacteria occurs in two different steps generally. 1)
Direct interaction between the surface and bacterial outer membrane causing the membrane to rupture. 2) Formation of holes in the outer membrane through which the cell loses vital nutrients and water causing a general weakening of the cell. Normally bacteria, viruses, and fungi all depend on an enzyme to metabolize oxygen to live. Copper interferes with the effectiveness of these enzymes and disables the uptake of oxygen and thereby killing the microbes [6]. It is also supposed that microorganisms carry a negative charge while metal nanoparticles carry a positive charge. This creates an electromagnetic attraction between the microbe and particles surface. Once the contact is made, the microbe is oxidized and dead instantly [20].

Table 2: Synergistic effect of different antibiotics with and without nano copper against gram-negative bacteria

\begin{tabular}{|c|c|c|c|c|c|c|c|c|}
\hline \multirow{3}{*}{$\begin{array}{l}\text { Antibiotics } \\
(\mu \mathrm{g} / \text { disc })\end{array}$} & \multicolumn{4}{|c|}{ Escherichia coli } & \multicolumn{4}{|c|}{ Pseudomonas aeruginosa } \\
\hline & \multicolumn{2}{|c|}{ Zone of inhibition (mm) } & \multirow{2}{*}{$\begin{array}{l}\text { Increased } \\
\text { zone size } \\
(\mathrm{mm})\end{array}$} & \multirow{2}{*}{$\begin{array}{l}\text { Fold } \\
\text { Increase } \\
(\%)\end{array}$} & \multicolumn{2}{|c|}{ Zone of inhibition (mm) } & \multirow{2}{*}{$\begin{array}{l}\text { Increased } \\
\text { zone size } \\
(\mathrm{mm})\end{array}$} & \multirow{2}{*}{$\begin{array}{l}\text { Fold } \\
\text { Increase } \\
(\%)\end{array}$} \\
\hline & $\begin{array}{l}\text { Antibiotic } \\
\text { alone }\end{array}$ & $\begin{array}{l}\text { Antibiotic+ } \\
\text { CuNPs }\end{array}$ & & & $\begin{array}{l}\text { Antibiotic } \\
\text { alone }\end{array}$ & $\begin{array}{l}\text { Antibiotic+CuNP } \\
\text { s }\end{array}$ & & \\
\hline Tetracycline $\left(\mathrm{T}_{30}\right)$ & $14.33 \pm 0.47$ & $20.67 \pm 0.47$ & $6.33 \pm 0.47$ & 44.17 & $13.00 \pm 0.41$ & $19.67 \pm 0.94$ & $6.67 \pm 1.31$ & 51.31 \\
\hline Rifampicin $\left(\mathrm{R}_{5}\right)$ & $6.00 \pm 0.00$ & $10.83 \pm 0.24$ & $4.83 \pm 0.24$ & 80.50 & $12.67 \pm 1.25$ & $17.33 \pm 0.47$ & $5.00 \pm 1.41$ & 39.46 \\
\hline Chloramphenicol & $22.33 \pm 1.69$ & $26.83 \pm 0.24$ & $4.50 \pm 1.78$ & 20.15 & $26.00 \pm 0.41$ & $27.17 \pm 0.85$ & $1.17 \pm 0.62$ & 45.00 \\
\hline$\left(\mathrm{C}_{30}\right)$ & $6.00 \pm 0.00$ & $12.00 \pm 0.00$ & $6.00 \pm 0.00$ & 100.00 & $11.00 \pm 0.82$ & $18.33 \pm 0.62$ & $7.33 \pm 1.18$ & 66.64 \\
\hline Vancomycin $\left(\mathrm{VA}_{30}\right)$ & $16.40 \pm 0.99$ & $20.33 \pm 1.25$ & $3.93 \pm 0.74$ & 23.96 & $15.33 \pm 0.24$ & $19.00 \pm 1.63$ & $3.67 \pm 1.84$ & 23.94 \\
\hline Gentamycin $\left(\mathrm{G}_{10}\right)$ & $11.67 \pm 1.25$ & $21.00 \pm 0.82$ & $9.33 \pm 2.05$ & 79.95 & $6.00 \pm 0.00$ & $8.67 \pm 0.62$ & $2.67 \pm 0.62$ & 44.50 \\
\hline Streptomycin $\left(\mathrm{S}_{10}\right)$ & $14.67 \pm 0.94$ & $17.67 \pm 1.25$ & $3.00 \pm 0.82$ & 20.45 & $12.83 \pm 0.94$ & $14.17 \pm 0.62$ & $1.33 \pm 1.55$ & 10.37 \\
\hline Kanamycin $\left(\mathrm{K}_{30}\right)$ & $11.33 \pm 0.34$ & $19.17 \pm 0.24$ & $7.83 \pm 0.53$ & 69.11 & $11.33 \pm 1.03$ & $17.50 \pm 1.22$ & $6.17 \pm 1.25$ & 54.46 \\
\hline Tobramycin $\left(\mathrm{TB}_{10}\right)$ & $6.00 \pm 0.00$ & $11.00 \pm 0.82$ & $5.00 \pm 0.82$ & 83.33 & $9.33 \pm 0.62$ & $12.67 \pm 0.94$ & $3.33 \pm 0.62$ & 35.69 \\
\hline \multirow{2}{*}{$\begin{array}{l}\text { Penicillin }\left(\mathrm{P}_{10}\right) \\
\text { Ampicillin }\left(\mathrm{A}_{10}\right)\end{array}$} & $11.17 \pm 0.85$ & $14.00 \pm 0.82$ & $2.83 \pm 0.62$ & 25.34 & $13.17 \pm 0.85$ & $16.50 \pm 1.22$ & $3.33 \pm 0.47$ & 25.28 \\
\hline & \multicolumn{3}{|c|}{ Overall synergistic bactericidal effect (\%) } & 54.70 & \multicolumn{3}{|c|}{ Overall synergistic bactericidal effect (\%) } & 39.64 \\
\hline
\end{tabular}

Each value is the mean \pm SD of triplicate analysis

Table 3: Synergistic effect of different antibiotics with and without nano copper against gram-positive bacteria

\begin{tabular}{|c|c|c|c|c|c|c|c|c|}
\hline \multirow{3}{*}{$\begin{array}{l}\text { Antibiotics } \\
\text { ( } \mu \mathrm{g} / \mathrm{disc})\end{array}$} & \multicolumn{4}{|c|}{ Bacillus cereus } & \multicolumn{4}{|c|}{ Staphylococcus aureus } \\
\hline & \multicolumn{2}{|c|}{ Zone of inhibition (mm) } & \multirow{2}{*}{$\begin{array}{l}\text { Increased } \\
\text { zone size } \\
(\mathrm{mm})\end{array}$} & \multirow{2}{*}{$\begin{array}{l}\text { Fold } \\
\text { Increase } \\
(\%)\end{array}$} & \multicolumn{2}{|c|}{ Zone of inhibition (mm) } & \multirow{2}{*}{$\begin{array}{l}\text { Increased } \\
\text { zone size } \\
(\mathrm{mm})\end{array}$} & \multirow{2}{*}{$\begin{array}{l}\text { Fold } \\
\text { Increase } \\
(\%)\end{array}$} \\
\hline & $\begin{array}{l}\text { Antibiotic } \\
\text { alone }\end{array}$ & $\begin{array}{l}\text { Antibiotic+ } \\
\text { CuNPs }\end{array}$ & & & $\begin{array}{l}\text { Antibiotic } \\
\text { alone }\end{array}$ & $\begin{array}{l}\text { Antibiotic+CuNP } \\
\text { s }\end{array}$ & & \\
\hline Tetracycline $\left(\mathrm{T}_{30}\right)$ & $17.83 \pm 0.85$ & $28.50 \pm 0.82$ & $10.66 \pm 0.24$ & 59.79 & $25.33 \pm 1.25$ & $32.67 \pm 2.05$ & $7.33 \pm 1.89$ & 28.94 \\
\hline Rifampicin $\left(\mathrm{R}_{5}\right)$ & $8.50 \pm 0.41$ & $15.17 \pm 0.85$ & $6.67 \pm 1.25$ & 78.47 & $19.33 \pm 0.94$ & $22.00 \pm 1.63$ & $2.67 \pm 1.89$ & 13.81 \\
\hline Chloramphenicol $\left(\mathrm{C}_{30}\right)$ & $25.67 \pm 0.62$ & $29.83 \pm 0.85$ & $4.17 \pm 1.25$ & 16.24 & $20.00 \pm 0.00$ & $23.00 \pm 1.47$ & $3.00 \pm 1.47$ & 15.00 \\
\hline Vancomycin $_{\left(\mathrm{VA}_{30}\right)}$ & $6.00 \pm 0.00$ & $12.00 \pm 0.00$ & $6.00 \pm 0.00$ & 100.00 & $18.33 \pm 0.62$ & $20.00 \pm 1.63$ & $1.67 \pm 1.02$ & 9.11 \\
\hline Gentamycin $\left(\mathrm{G}_{10}\right)$ & $17.67 \pm 1.25$ & $21.83 \pm 1.43$ & $4.17 \pm 0.24$ & 23.60 & $21.17 \pm 1.03$ & $22.67 \pm 1.25$ & $1.50 \pm 0.41$ & 7.09 \\
\hline Streptomycin $\left(\mathrm{S}_{10}\right)$ & $13.00 \pm 0.82$ & $16.17 \pm 0.85$ & $3.17 \pm 1.03$ & 24.38 & $20.67 \pm 0.47$ & $23.00 \pm 1.63$ & $2.33 \pm 1.70$ & 11.27 \\
\hline Kanamycin $\left(\mathrm{K}_{30}\right)$ & $11.00 \pm 1.63$ & $18.50 \pm 0.82$ & $7.50 \pm 0.82$ & 68.18 & $23.33 \pm 1.03$ & $25.17 \pm 1.03$ & $1.83 \pm 1.03$ & 7.84 \\
\hline Tobramycin $\left(\mathrm{TB}_{10}\right)$ & $12.17 \pm 0.85$ & $19.67 \pm 1.03$ & $7.50 \pm 1.78$ & 61.63 & $21.00 \pm 0.82$ & $21.67 \pm 0.47$ & $0.67 \pm 0.47$ & 3.19 \\
\hline Penicillin $\left(\mathrm{P}_{10}\right)$ & $6.00 \pm 0.00$ & $10.00 \pm 0.82$ & $4.00 \pm 0.82$ & 66.67 & $24.00 \pm 0.82$ & $25.50 \pm 0.82$ & $1.50 \pm 0.00$ & 6.25 \\
\hline \multirow[t]{2}{*}{ Ampicillin $\left(\mathrm{A}_{10}\right)$} & $12.17 \pm 1.31$ & $14.33 \pm 0.62$ & $2.17 \pm 1.25$ & 17.83 & $30.33 \pm 1.03$ & $32.33 \pm 0.62$ & $2.00 \pm 1.41$ & 6.59 \\
\hline & \multicolumn{3}{|c|}{ Overall synergistic bactericidal effect (\%) } & 51.68 & \multicolumn{3}{|c|}{ Overall synergistic bactericidal effect (\%) } & 10.91 \\
\hline
\end{tabular}




\section{Each value is the mean \pm SD of triplicate analysis}

\section{Combined effect of copper nanoparticles with antibiotics}

The combined effect of copper nanoparticles with different commercial antibiotics was investigated against the selected bacterial pathogens. Diameter of inhibition zone around different antibiotics with and without CuNPs against the tested strains is given in tables 2 and 3 .

A minimum zone of inhibition was increased from $0.67 \pm 0.47 \mathrm{~mm}$ to $10.66 \pm 0.24 \mathrm{~mm}$ when nanoparticles and the antibiotics were given together. The antibacterial activities of all the antibiotics have been increased in the presence of copper nanoparticles against tested pathogens. The highest fold increase in area was observed for Streptomycin $(9.33 \pm 2.05 \mathrm{~mm})$, Vancomycin $(7.33 \pm 1.18 \mathrm{~mm})$ and Tetracycline $(10.66 \pm 0.24 \mathrm{~mm}$ and $7.33 \pm 1.89 \mathrm{~mm})$ against Escherichia coli, Pseudomonas aeruginosa, Bacillus cereus, and Staphylococcus aureus respectively. The lowest fold increase in area $(0.67 \pm 0.47 \mathrm{~mm})$ was observed against Staphylococcus aureus for the antibiotic Tobramycin. Among the tested strains, Escherichia coli exhibited maximum synergistic bactericidal effect (54.70\%) followed by Bacillus cereus (51.68\%), Pseudomonas aeruginosa (39.67\%) and Staphylococcus aureus (10.91\%). The observed enhancement of antibacterial activity in the present experimental condition could be due to the antibiotic-nanoparticle combination and not to the effect of CuNPs itself. There are several studies have been carried out on the antibacterial efficacies of nanoparticleantibiotic combinations, but little is known about interactions between antibiotics and copper nanoparticles. Interactions between different antibiotics and silver nanoparticles produced by bacteria and fungi were investigated earlier [21, 22]. Combining nanoparticles with antibiotics not only reduce the toxicity of both agents towards human cells by decreasing the requirement for high dosages but also enhances their bactericidal properties. Synergistic effect of copper nanoparticles with antibiotics may be due to the certain complex formation which becomes more effective in the inhibition of a particular species of microorganisms either by inhibiting the cell wall synthesis or by causing its lysis or death [23].

\section{CONCLUSION}

Nanobiotechnology is an important area of research that deserves all our attention owing to its potential application to fight against antibiotic-resistant pathogens. The present study illustrates a simple, convenient and significant method for the synthesis of copper nanoparticles through the reduction of copper salts using sodium borohydride as a reducing agent. From this work, it is concluded that copper nanoparticles impregnated with antibiotics exhibit profoundly stipulated inhibitory effects. This enhancement in the combined effect is preferably due to the difference in the mechanism of inhibition followed by nanoparticles and antibiotics. Hence our results suggest that copper nanoparticles may be suitable for combating pathogenic microorganisms.

\section{ACKNOWLEDGMENT}

The author is very grateful to the Managing board, V. V. Vanniaperumal College for Women for providing facilities and Alagappa University, CECRI, Karaikudi for technical assistance.

\section{AUTHORS CONTRIBUTIONS}

The Author Dr. M. Selvarani designed and carried out the experiment as well as prepared the manuscript.

\section{CONFLICT OF INTERESTS}

The author declares that there is no conflict of interests

\section{REFERENCES}

1. Lara HH, Ayala-Nunez NV, Turrent LCI, Padilla CR. Bactericidal effect of silver nanoparticles against multidrug-resistant bacteria. World J Microbiol Biotechnol 2010;26:615-21.

2. Song X, Sun S, Zhang W, Yin Z. A method for the synthesis of spherical copper nanoparticles in the organic phase. J Colloid Interf Sci 2004;273:463-9.
3. Li ZQ, Mao YZ, Jun DB, Zhe LX, Juan GY. Preparation of copper nanoparticles by chemical reduction method using potassium borohydride. T Nonferr Metal Soc 2010;20:240-4.

4. Vincent M, Hartemann P, Engels-Deutsch M. Antimicrobial applications of copper. Int J Hyg Environ Heal 2016;219:585-91.

5. Zhang HX, Siegert U, Liu R, Cai WB. Facile fabrication of ultra copper nanoparticles in organic solvent. Nanoscale Res Lett 2009;4:705-8.

6. Theivasanthi T, Alagar M. Nanosized copper particles by electrolytic synthesis and characterizations. Int J Phys Sci 2011;6:3726-35.

7. Raffi M, Mehrwan S, Bhatti TM, Akhter JI, Hameed A, Yawar W, et al. Investigation into the antibacterial behavior of copper nanoparticles against Escherichia coli. Ann Microbiol 2010;6:7580.

8. Cioffi N, Ditaranto N, Torsi L, Picca RA, Sabbatini L, Valentini A et al. Analytical characterization of bioactive fluoropolymer ultra-thin coatings modified by copper nanoparticles. Anal Bioanal Chem 2005;38:607-16.

9. Ramyadevi J, Jeyasubramanian K, Marikani A, Rajakumar G, Rahuman A. Synthesis and antimicrobial activity of copper nanoparticles. Mater Lett 2012;71:114-6.

10. Samim M, Kaushik NK, Maitra A. Effect of the size of copper nanoparticles on its catalytic behavior in Ullman reaction. Biomater Sci 2007;30:535-40.

11. Selvarani M, Prema P. Evaluation of antibacterial efficacy of chemically synthesized copper and zerovalent iron nanoparticles. Asian J Pharm Clin Res 2013;6:223-7.

12. Selvarani M, Prema P. Synergistic antibacterial evaluation of commercial antibiotics combined with nano iron against human pathogens. Int J Pharm Sci Rev Res 2013;18:183-90.

13. Mulvaney P. Surface plasmon spectroscopy of nanosized metal particles. Langmuir 1996;12:788-800.

14. Shahverdi AR, Fakhimi A, Shahverdi HR, Minaian S. Synthesis and effects of silver nanoparticles on the antibacterial activity of different antibiotics against Staphylococcus aureus and Escherichia coli. Nanomedicine 2007;3:168-71.

15. Mukhopadhyay R, Kazi J, Debnath MC. Synthesis and characterization of copper nanoparticles stabilized with Quisqualis indica extract: evaluation of its cytotoxicity and apoptosis in B16F10 melanoma cells. Biomed Pharmacother 2018;97:1373-85.

16. Fatma S, Kalainila P, Ernest Ravindran RS, Renganathan S. Green synthesis of copper nanoparticles from Passiflora foetida leaf extract and its antibacterial activity. Asian J Pharm Clin Res 2017;10:223-79-83.

17. Ram Prasad S, Elango K, Damayandhi D, Saranya JS Formulation and evaluation of azathioprine loaded silver nanoparticles for the treatment of rheumatoid arthritis. Asian J Biomed Pharm Sci 2013;3:28-32.

18. Saranyaadevi K, Subha V, Ernest Ravindran RS, Renganathan S. Synthesis and characterization of copper nanoparticles using Capparis zeylanica leaf extract. Int J Chemtech Res 2014;6:4533-41.

19. Bindhu MR, Umadevi M. Synthesis of monodispersed silver nanoparticles using Hibiscus cannabinus leaf extract and its antimicrobial activity. Spectrochim Acta Part A 2013;101:184-90.

20. Roy AS, Parveen A, Koppalkar AR, Prasad MVNA. Effect of nanotitanium dioxide with different antibiotics against methicillinresistant Staphylococcus aureus. J Biomater Nanobiotechnol 2010;1:37-41.

21. Birla SS, Tiwari VV, Gade AK, Ingle AP, Yadav AP, Rai MK Fabrication of silver nanoparticles by Phoma glomerata and its combined effect against Escherichia coli, Pseudomonas aeruginosa, and Staphylococcus aureus. Lett Appl Microbiol 2009;48:173-9.

22. Fayaz AM, Balaji K, Girilal M, Yadav R, Kalaichelvan PT, Venketesan R. Biogenic synthesis of silver nanoparticles and their synergistic effect with antibiotics: a study against gram-positive and gramnegative bacteria. Nanomedicine 2010;6:103-9.

23. Allahverdiyev AM, Kon KV, Abamor ES, Bagirova M, Rafailovich M. Coping with antibiotic resistance: combining nanoparticles with antibiotics and other microbial agents. Expert Rev Anti Infect Ther 2011;9:1035-52. 